\title{
Article
}

\section{Qualitative perspectives on how Manchester United Football Club developed and sustained serial winning.}

Horrocks, DE, McKenna, J, Whithead, A, Taylor, PJ and Morley, AM Available at http://clok.uclan.ac.uk/15760/

Horrocks, DE, McKenna, J, Whithead, A, Taylor, PJ ORCID: 0000-0002-99998397 and Morley, AM ORCID: 0000-0003-1942-1983 (2016) Qualitative perspectives on how Manchester United Football Club developed and sustained serial winning. International Journal of Sports Science \& Coaching, 11 (4). pp. 467-477. ISSN 1747-9541

It is advisable to refer to the publisher's version if you intend to cite from the work. http://dx.doi.org/10.1177/1747954116655053

For more information about UCLan's research in this area go to http://www.uclan.ac.uk/researchgroups/ and search for <name of research Group>.

For information about Research generally at UCLan please go to http://www.uclan.ac.uk/research/

All outputs in CLoK are protected by Intellectual Property Rights law, including Copyright law. Copyright, IPR and Moral Rights for the works on this site are retained by the individual authors and/or other copyright owners. Terms and conditions for use of this material are defined in the policies page.

\section{CLoK}

Central Lancashire online Knowledge www.clok.uclan.ac.uk

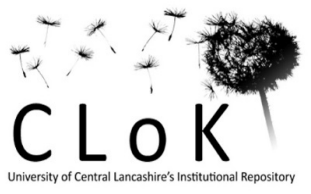




\title{
International Journal of Sports Science and Coaching: 2016, 11(5)
}

\section{Qualitative perspectives on how Manchester United Football Club developed and sustained serial winning.}

\author{
David E. Horrocks ${ }^{1,2}$, Jim McKenna ${ }^{3}$, Amy Whitehead ${ }^{4}$, Paul J. Taylor ${ }^{1}$, Andy M. Morley ${ }^{1}$ \\ ${ }^{1}$ School of Psychology, University of Central Lancashire, Preston, UK E-mail: $\underline{\text { d.horrocks2@uclan.ac.uk }}$ \\ ${ }^{2}$ International Centre for Football Research, UCFB Burnley and Wembley, \\ ${ }^{3}$ Institute of Sport, Physical Activity and Leisure, Leeds Beckett University, \\ ${ }^{4}$ School of Education, Leisure and Sports Studies, Liverpool John Moores University,
}

\begin{abstract}
Talent development in sport is well represented in scientific literature. Yet, the drive to protect 'trade secrets' often means that access to these high performing groups is rare, especially as these high level performances are being delivered. This leaves the details of high-end working practices absent from current academic commentary. As a result, clubs interested in developing excellent practice are left to build on personal initiative and insight and/or custom-and-practice, which is unlikely to yield successful outcomes. To address this shortfall the current study reports on prolonged engagement with a single high performing club, considering how their practice corresponds with existing sport talent development models. The paper ends by proposing an evidence-based, football-specific model for talent development, maintained high level performance and serial winning. This model emphasises four dominant features: culture, behavioral characteristics, practice engagement and the managing and guiding of performance 'potential'. The study provides insights into the visceral reality of daily experiences across the life course of professional soccer, while advancing the evidence-base for understanding how Manchester United achieved their serial success.
\end{abstract}

Key words: Football, Expertise, Talent Identification and Development 


\section{INTRODUCTION}

At the professional level, association football ('football') is a global business. Further, to secure its longevity, millions of pounds are spent annually by professional football clubs and governing bodies on unearthing and developing the next generation of players. As an indication of their commitment to this important process, in the UK The FA Premier League recently invested $£ 320 \mathrm{~m}$ in the delivery of a new player development system, the Elite Player Performance Plan (EPPP). EPPP focuses on four key fundamentals: improving coaching provision; effective measurement; significant gains in player development and player education [1]. This paper investigates the theory of football development through consideration of existing football-specific research and sports talent development models. The study compares the theory with practice in one of the world's most successful youth development systems, Manchester United Football Club.

Extensive literature has emerged over recent decades on expert performance and talent development in both the scientific [2-6] and the popular press [7-12]. However, the most cited peer-reviewed author in this domain, Anders Ericsson, suggests that expert performance is domain-specific and warrants specific and individual investigation to ascertain the true characteristics of such phenomena [2]. While Ericsson has been misquoted as suggesting the need for the equivalent of 10 years, or 10,000 hours, experience to attain expertise, inevitably the use of any bland numeric expression overlooks the domain and sport-specific developments needed to become a professional athlete. Indeed, considerable variation is possible in the ways that deliberate practice is undertaken [2,13]. On the one hand, there is support for the positive linear relationship between practice time and skill level for soccer players [14]. Another perspective is that because of the repetitive nature, athletes require high levels of self-motivation to handle that challenge; self-motivation itself may be a product of the way any given system is deployed or even a required characteristic for selection into a particular programme. Ericsson [3] certainly refers to the importance of athlete maturity to manage the lack of immediate reward or gratification while deliberately practicing.

The theories of deliberate practice and models of talent development each provide key insights into an athlete's progress and development towards elite level status. However, it is important to note that different performance environments require different levels of deliberate practice at different stages of development [3]. Ericsson [6] further details the complexity of expert performance by describing it as a series of activities involving execution, monitoring, planning and analysis of performance, each of which hinges - to some degree - on being supported by a coach and supplemented by additional sportspecific expertise. It is highly likely, then, that given the elusive nature of serial winning, that any club with such a track record will demonstrate superiority in some aspects of their approach to talent development.

Typically, talent development models characterise athletes in stages, describing each stage according to athletes' dominant features and needs as they develop through childhood, youth and adulthood [1517]. The need for further development is also important at the top end of performance, even though most models suggest that champions simply require a maintenance stage $[16,18]$. In this understanding, existing models [15-17] represent an incomplete understanding of the whole developmental sequence; the wide variability of performance level that exists among fully professional football players confirms this. Indeed, Kreiner-Phillips and Orlick [19] highlight the difference between becoming a word class performer, and maintaining the results of a world class performer. It has also been suggested that far from requiring 'maintenance', at this stage athletes require better quality training and even more support to deal with the additional stress of performing at an elite level [18].

In this understanding, it is clear that existing and/or generic models can no longer be relied upon to indicate the refinements that elite-level football players need to sustain serial success once they have progressed into the elite level. With millions of pounds being invested annually in both football development and performance of existing senior level teams, and a requirement to play at a high level more than once per week, it is evident that a more nuanced model of higher level performance is 
required. This is especially important for sports where the inherent demands require serial success. Yet, their development has been largely unexplored in football, except through hagiographies of elite-level players and in retrospective isolated accounts. This leaves a clear gap in the current literature for a more robust football talent development model that derives from participants who are at the pinnacle of the game. The objective of this study is to consider the alignment of existing literature with the detailed accounts of people directly and indirectly involved with the sustained high performance at all stages of Manchester United.

\section{METHOD}

\section{CONTEXT}

A qualitative study was carried out at Manchester United Football Club of the English FA Premier League. Underlining the commitment of the club to youth and talent development, a player produced by Manchester United's academy featured in every game of the 1500 where manager, Sir Alex Ferguson, was in charge, from 1986 to 2013 [20]. Prior to that at least one home grown player had been in United's match day squads for 3,638 consecutive games [21]. It is also important to confirm that the participants and the club meet the criteria for 'elite' based on performance, which explains this next section.

\section{PARTICIPANTS}

Recruitment and access was obtained by the first author who has a background as a youth level professional player and senior level professional coach. This personal history was key to establishing participant trust, and for securing a nuanced 'insider' perspective [22] of the distinctive approaches employed in this club. Five participants were recruited: three players, one coach and one parent of an elite-level player. This created the opportunity to triangulate themes across the respective contributor constituencies. In total, the player participants made over 1000 appearances for the club: one player came to the club as an existent maintenance stage professional and went on to make over 350 appearances and captained his country at full international level while representing Manchester United. Two players came through the Manchester United youth system and were members of the lauded "Class of '92" [23], which represents a narrative depicting how a group of 14-year-olds passed through this club's youth development system to become global stars through unprecedented football success.

The three player participants played at Manchester United from ages 11 through to retirement and within this period of engagement the club won 48 major trophies. Between them they won multiple FA Youth Cups, Youth International European championships, youth and reserve leagues, FA Premier League titles, FA Cups, European Champions leagues and World Club Championships. The players were at the pinnacle of the game throughout their lifespan in the club and met most standards for serial success. The coach participant worked at the club for $20+$ years, coaching at all levels. The parent had supported his son from being an academy schoolboy to playing in the European Champions League.

\section{PROCEDURE}

The study adopted an interview process in the form of retrospective qualitative interview recommended for tracing the development of athletes [24]. Interviews were pilot tested for quality and rigor with a volunteer professional footballer. Pilot testing was conducted and refined in association with two authors; this method created a process that could establish the experiences of the participants and provide an interpretive account of daily life [25].

Institutional ethical approval was secured and informed consent was obtained from all participants. A semi-structured interview was designed to allow the three players and the coach to discuss life at Manchester United Football Club. Topics included: the working life within the club; the culture and environment; the lifestyles; the training and match specific practices; behaviors on and off the field of 
play; the learning process; the development and maintenance of such a career; the mentality of the serial-winning organization; and the evolution and maintenance of such levels of performance over time. This provided an existential snapshot on what being a serial-winning Manchester United player or coach involved, from childhood to retirement.

The parent-participant was recruited to provide the perspective of an 'outside' supportive significant other. In his case we discussed what life involved bringing up a son employed within the club. Confidentiality was assured in line with standard academic procedure, although it is worth noting that this was not a large concern for these participants; their lives have already been, and continue to be, lived in the public domain. Notes of the players' achievements are provided within the text to confirm elite status. While this may allude to the players' identities they understood and accepted this from the outset.

Interviews lasted between 60 and $120 \mathrm{~min}$, supplemented by preamble, introduction, briefing, and personal assurances. Five interviews took place, supplemented by five further meetings - one per contributor - to clarify accurate transcription and to member check/validate interpretations.

\section{TRANSCRIPTION}

Jeffersonian transcription analysis [26] was used to annotate the participant recordings. The Jeffersonian method is designed to capture not only what was said but the way in which it was said. Emotion, manner, tone, relativity and reasoning are all captured through this approach (Key: (.) micro pause, a notable pause but of no significant length, (1) A timed pause, long enough to show in transcription to express tone, emotion and visceral reality of prose, (2) an extended timed pause). Piloting had confirmed the utility of this approach for discussing life in a football.

\section{DATA ANALYSIS}

All interviews were transcribed verbatim and an inductive content analysis was employed following the recommendations of Côté et al [27]. During this process, transcripts were checked and cross-referenced by four researchers to identify triangulated themes and to establish their connectivity. Themes were then clustered into higher order themes; each theme is represented by a participant quotation data in the transcript to avoid researcher bias. Quotes were selected for the richness of the passages for highlighting that theme. Data were then compared and contrasted with existing developmental models to construct an evidence-framework detailing the operating procedure of Manchester United players. Data was analysed in line with the principles of Huberman's approach [25]. This procedure involves data reduction, data display, conclusion hypothesis, and verification procedures.

\section{RESULTS}

The outcomes are provided in two sections. Section 1 is a thematic indicator of the overall behaviours and commitments described by participants. Section 2 comprises quotations from the interviewees. Analysis identified four stages of development in the journey to becoming a consistently high performing footballer and a fifth stage of evolutionary excellence. 


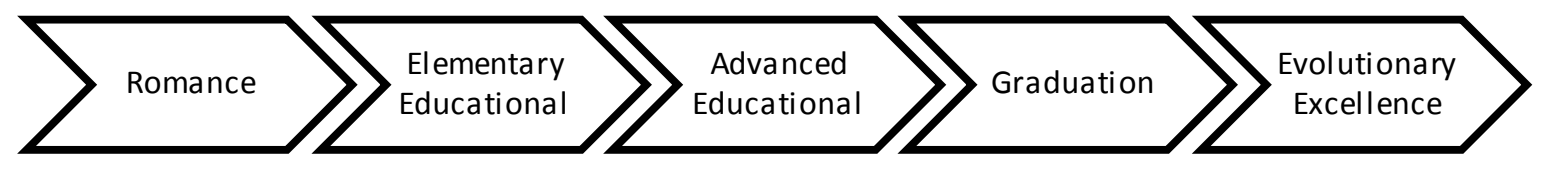

1. Romance - deliberate play and curiosity, age 8-11

2. Elementary Educational - early education phase within the academy structure, age 11-15.

3. Advanced Educational - youth team, age 16-18, reserve and underage international player age $16-21$.

4. Graduation - developing as a first team player

5. Evolutionary Excellence - serial winning first team player and regular full international player.

\section{ROMANCE - DELIBERATE PLAY AND CURIOSITY.}

In this stage players were falling in love with the game and adopting a curious, playful, yet unconsciously deliberate engagement linked to a dream of athletic life.

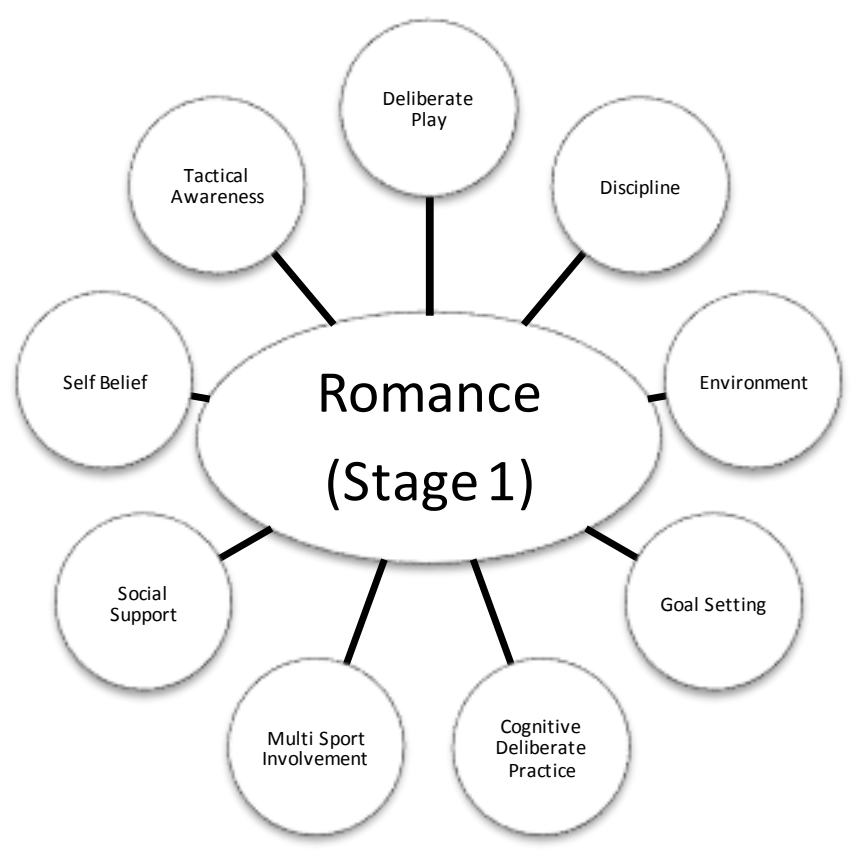

- Player A: we played a game called 'Change' (.) you have to get from one side of the road to the other (.) starting with one person in the middle and 10-15 kids at the sides (1) if you get 'tigged' you went in the middle (.) I would never get 'tigged' first 
- Player B: hurling and Gaelic football (.) chess (.) er (.) I played chess at a very high level (.) football and soccer (.) football predominantly

In this 'early years' stage there was an enjoyable approach to multi-sport involvement, deliberate play and sampling. The activities assisted physical development, tactical decision-making, focus and a competitive self-belief.

- Parent: you could hear (.) well (.) 7/8 o'clock at night before he went to come in for bed (.) it were bang-bang-bang (.) and he was setting himself(.) or I'd set him (.) sometimes if I were walking past or went to watch him do these practices (.) set him some targets

Goal setting, parental support, extensive often intense hours of practice, discipline, deliberate technical perfection and personal motivation outline the most pervasive forms of reported behaviour. All of this began from an early age and long before players had considered specializing in football. There is also evidence of players sampling the sport with a purpose and in a deliberately playful manner.

- Player A: so it'd be (.) ya know (.) it'd be PE(.) a PE lesson (.) it could be a football training session (.) or a lesson at school (1) but there was always something throughout the week that you'd look forward to (.) and that's what I did (1) you look forward to them (.) obviously more so than (.) more more the football but sport in general ya know

Player A clearly demonstrates being inspired by involvement in sport. This internal motivation was also characterized by enthusiastic anticipation of participation in sport in a school offering opportunities for regular and meaningful involvement.

\section{ELEMENTARY EDUCATIONAL - EARLY EDUCATION PHASE WITHIN THE ACADEMY STRUCTURE}

Here players were selected for their potential for advancement through an organised structure under professional guidance.

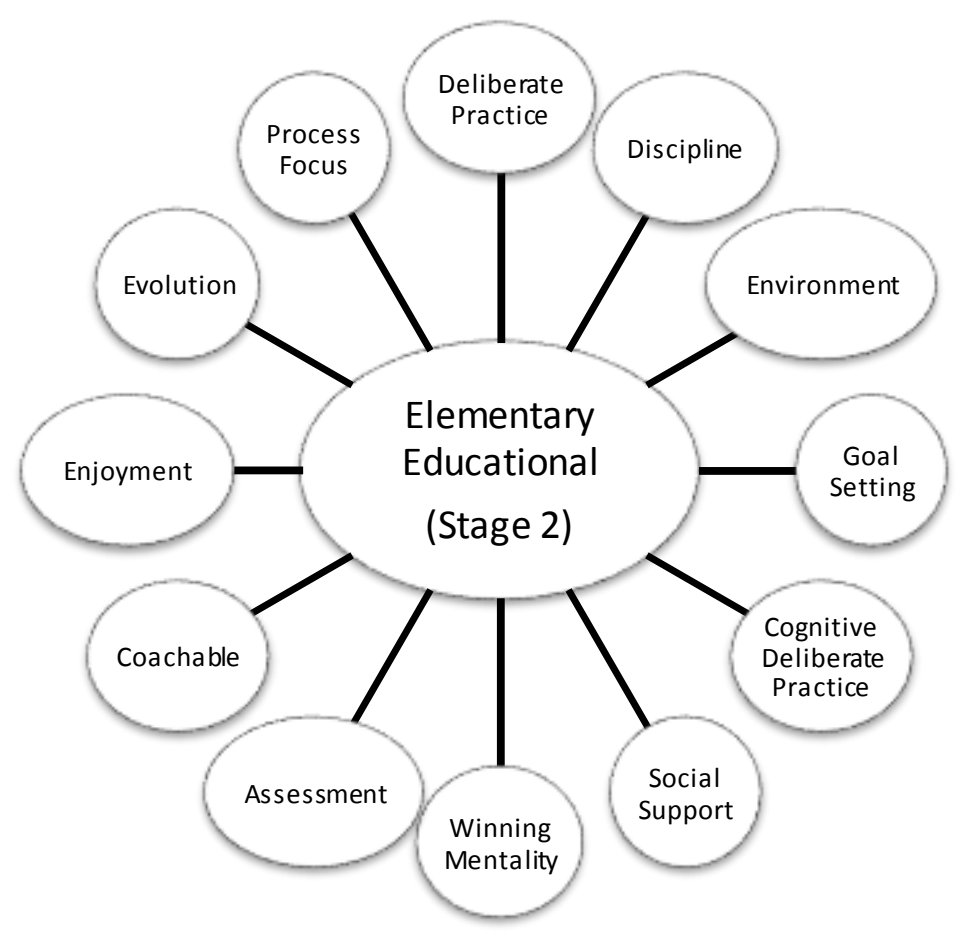


- Coach: at the age of 12 you're not developing the player (.) you're developing a character (.) a spirit a person you know (1) I think certain players (.) their character can sometimes affect them as a player (.) so I think you're not just building a player (.) you're building a character and spirit (.) about doing the right things (.) and everything that culture tells you as a 12 year old (1) I suppose it's like your teacher really at school (1) you'll actually hang off their every word and if they get that wrong you're in trouble

Here there is clear evidence that the football club provided a structure for developing the extensive requirements of players in this academy. The coach expands on this idea noting the attention paid to personal characteristics, discipline, environment, culture, and support. The system was designed to offer a controlled, influential education, even at this young age.

- Player A: I got Trevor Steven's shirt and I never stopped wearing it (1) when I went up and played on the pitch I'd wear it and I'd try and be like Trevor Steven ya know (.) the way I'd act and the way I'd go past people (2) it was difficult but I always remember he was probably the first person I looked at and thought yeah ya know (.) he had an influence on me

Players commonly mentioned sacrificing personal time to self-reflection and deliberate cognitive practice. Modelling was clearly important in this early stage and having strong models was important; models provide a living, visible 'evidence-base' of the behaviors, routines and approaches that the developing player can use to create their own framework of what it takes to become a successful player. Further, models help players in similar positions to understand the technical game processes. Seeing a successful player doing these things helps players to commit to these new ideas in his practice. Their proximity allows younger players to mimic physical movements, to recheck on progress and to acquire similar (or even improved) behavioral nuances that contribute to making the young player successful and competitive. This process was accentuated not only by the closeness of current elite players but also by historically important players ('legends') presence adding to the inspiration afforded by being in the academy;

- Player C: you would have European cup winners and World cup winners watching you training (2) you'd got Bobby Charlton and Nobby Stiles watching (.) they're actually involved in your development and we were very privileged to have that (1) training changed and went from almost like a session which is just (.) like you say (.) coaching coming in and putting cones out to people (.) telling you about experiences of how they made it and how they did it and (1) it just inspired you greatly (2) the sessions were obviously always interesting as well (.) always based around technical development and they were competitive (.) particularly in those early years

These quotes illustrate the collective power of inspiration, processes, goals and competitive intensity in an enjoyable manner. Importantly, this requires particular qualities of 'legends' to teach and develop future prospects; putting out the cones and son on, points to a form of humility and attention-to-detail on their part. Equally, these players appeared particularly receptive and willing to respond to the contributions made by these senior figures.

\section{ADVANCED EDUCATIONAL - YOUTH TEAM,AGE 16-18, RESERVE AND UNDERAGE INTERNATIONAL PLAYER}

This stage signaled the end of school and childhood and entry into an adult world of 'higher' education regarding life as a professional player. 


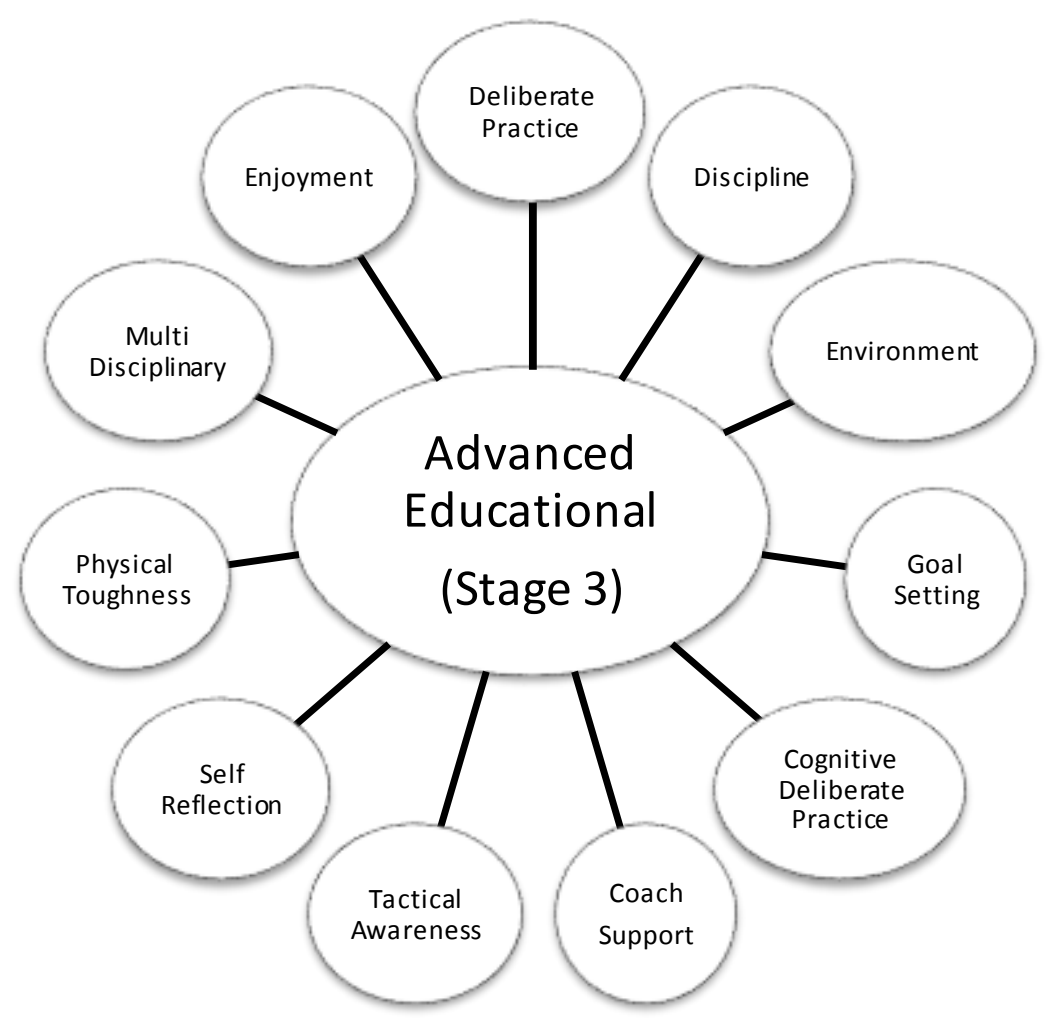

- Coach: I'd say to him (.) watch Brian Robson because you're going to replace Brian Robson and I want you to watch his every movement (.) you won't enjoy the game like the ordinary supporter but I mean (.) you'll get a lot more knowledge if you do it that way (1) you had to do it and you had to think about it (.) they learnt so much out of watching the first team play as a team or as an individual (.) and it's not easy for a young lad (.) because of the enjoyment factor (.) but that's how you learn (.) you learn watching the best players in the world

This passage provides an example of junior payers being connected to a positive playing trajectory. To deliver on this expectation, players were expected to be professionally focused, cognitively alert, accountable and goal-driven. At this point, enjoyment was expected to take a back seat to allow the 'work' to become more prominent. These characteristics were important so the players could assess and learn from the subtleties provided by an expert model. Players were expected to develop as they acquired an expansive position- and situation-specific knowledge base about Manchester United players, philosophies, and teamoperations. Long-term and long-term working memories are both being developed from such learning. Tactical awareness, information processing, decision making, reaction times and situation-specific confidence would all be nurtured through such cognitive engagement.

- Player C: 16 to 19 you were just fighting like mad(.) you are just doing everything (.) you just (.) I mean we all did, (.) you just do everything (1) you trained morning afternoon (.) you listened (.) you questioned (.) you just did everything you could

At this stage, unlike any that preceded it, players were committed to extended hours of self focused, deliberate and determined, repetitive practice. This involved mind and body development to sustain extensive physical toughness and to pursue the sheer hard work of additional practice and training that helped individuals to stand out.

- Player C: we were shown examples of the Milan team of the early 90s when they had Baresi and Costacurta (1) we were took into the rooms to watch them for 45 minutes (.) about aggressive defending (.) about pushing up (.) about when the ball was back you move up and 
when it (1) you know (.) you have to be shown examples as early as possible (.) live examples of how to do things and good principals

- Player A: my first contact was with a nutritionist and I was about 18 (.) 19 (1) he would take your body fat (.) and I would have it done every Friday and he'd get the card out and you'd be 10.1 (1) if I'm over 10.1 (.) I'm upset (laughs) ya know (.) I've gotta get it under 10.1 or at least 10.1 (.) ya know (.) so I spose it's a sign of competition

- Player A: I used to see a speed coach (.) a sprint coach off my own back(1) I used to pay for him

In this stage, players were exposed to wider understanding about what can contribute to top level performance and the part they can play in that for Manchester United. This involved working with multi-disciplinary support services, namely, sport science, physical conditioning, nutrition and video analysis. Attention was now shifting from the immediacies of personal skills for playing football to a determined focus on what surrounds it. This included watching how other high quality players and teams play; internationally renowned teams and players were especially influential. Player $\mathrm{C}$ was particularly keen to emphasise the determined nature of this work and how it sat alongside the ongoing football-specific work.

- Player C: the coach used to get us in every month and sit us in there (2) I remember at the age of 17 being told at the end of Year 1, "You've got a real (.) you've surprised me (1) you've got a real chance of playing in the first team" (2) and I remember thinking (1), "Well if he thinks that and he sees that players go through into the first team (.) then I can start to believe it"...

In this intensive period, the academy environment was clearly facilitative, coaches offered support, and in turn their assessments were trusted and invested with predictive powers. The words and actions of the coaches were important to Player $\mathrm{C}$ in his development through the ranks of professional football.

\section{GRADUATION - DEVELOPING FIRST TEAM PLAYER}

The graduation stage supports transition and integration to the first team practice environment and playing in first team games. This stage involved pressured testing of all preceding education and learning. 


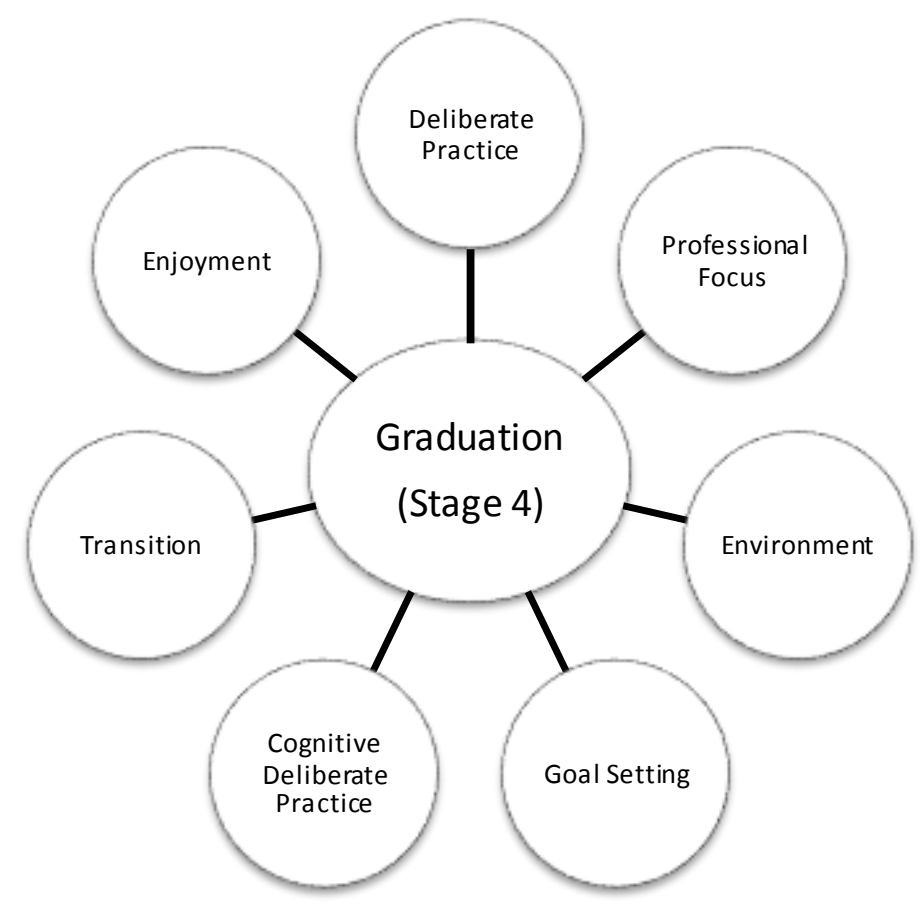

- Player B: I do wake and I do think about a game about how it's going to be what you're going to do (1) it would be very vivid and you'd always come out on top of course

Importantly, this intensified stage was prolonged, often over many years. To illustrate the intensity of their lives, players frequently described how consumed they were about their role in respective games and roles. They were 'shaping' their own identities as players and often this was more than what others understood as 'full-time'; work. This went beyond the obvious and conventional expressions of physical work to involve careful and predictable mental practice involving the visualization of success based on a process-orientated, solution-focused routine.

- Player C: I would say your next five years was getting into the first team(.) where I think you are at your most switched on (1) you're defining your career but that doesn't mean to say like (.) phew (.) I can relax now (.) that just means you're entering into a different phase of your actual development as a football player

Distinctive features of this stage included self-understanding, professional focus and delivering what was expected. There is an awareness of the developmental stages of ability and the transition from learner to trusted first team regular and a confidence in one's ability to make the transition.

- Coach: if you didn't do it right at Man United (.) you were down the road(1) it's as simple as that (.) because it was such a hard school (1) you've got to put big demands on players (.) especially if they wanted to play in the first team

Success in this context demanded discipline and high performance standards. An ability to cope with pressure demands, to learn from negative experiences (with or without the help of others) and to deliver consistent quality in one's work within the collective were important.

- Player A: the real enjoyment is the challenge of winning the training session or dominating the person thatyou're playing against (.) especially (.) like I say(.) throughout the development (.) once you got into the first team squad ya know (.) how would I play against (.) erm (1) Mark Hughes and Cantona (.) and invariably they'd get the better of you but there was no excuse (1) that was always a (.) ya know (.) the part of me (.) the analysing side of the training session 
after (.) ya know (.) and you'd think (.) ya know (.) Cantona made me look a bit stupid there (.) next time I'm not gonna do that

The capacity to replicate game culture and life in the first team environment was another contributory factor to serial success. The enjoyment - and emotional control - resulting from being regularly exposed to an intense and serious winning mentality, even in training sessions, perpetuated a goal-oriented discipline. This behaviour also nurtured the process of self-reflection and the ability to assess experience based on its merits.

- Player C: my biggest lesson in life that (.) and it was preparation costing you and (.) erm(.)I never took that risk everagain (1) I mean it just didn't happen in my career (1) to this day (.) I just never took the risk that I was never going to be involved. Preparation has been the key to my career.

\section{EVOLUTIONARY EXCELLENCE - SERIAL CLUB LEVEL WINNER AND REGULAR FULL INTERNATIONAL PLAYER.}

In this stage players continued to develop and refine their excellence by preparing for, and then delivering, consistently high level performance over an extended period.

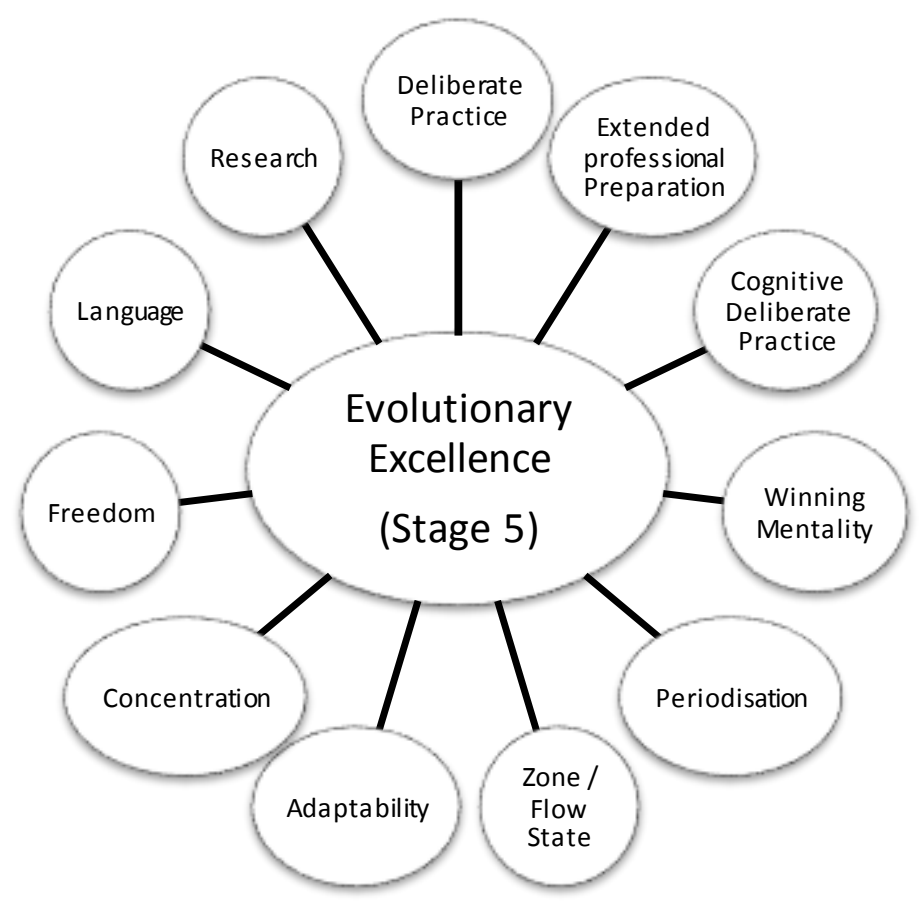

- Player C: I remember working on the Holland game (Competitive National team representative game) in Euro '96 (.) we worked on that particular match and that system for 5 months before (1). That performance wasn't a fluke.(\#)

In this stage, deliberate, extended, specific, tactical match practice and periodisation were highlighted. These features were understood as key to success in high-pressure, internationally competitive matches.

- Player B: the manager looks at ideas of how to win the game (.) and the vast majority of the team talks would be positive (.) which we do in training anyway (1) he always likes the side to 
attack (1) obviously he'd encourage us you know to try things get forward and that (1) I think it's the nature of the club

- Player C: in terms of the level of mindset in the changing room (.) mentally unbelievable (1) I think unbelievable and that's my bias but an unbelievable mindset (.) never ever to give in (.) never (.) sort of never say die (.) always just think you can win all the time and that shows in the performance (1) every game we come back in (.) every game we score in the last minute (.) that's come from the mindset of a manager who's just instilled it in a group of players

Another important feature here were the expressions the suggest 'knowing' about how to win a game, even in the last minute of play. This suggests the belief - the philosophy - was both evidence-based and experience-driven. Equally, understanding how training can be focused to win games while also creating a culture of positivity about expectations for winning were other essential components of serial success. This was complimented by a verbal structure that promoted the cognitive strength and belief that encouraged the team to attack, to trust themselves and one another and to play positive football. This culture ensured that winning was the players main (only?) foreseeable option, which enhanced commitment to individual episodes of play and relived anxieties about what opponents might do.

- Player C: I just felt that it didn't matter who I was playing against at that point (.) and there was probablyabout 7 or 8 years where I would say I felt just absolutely in a zone that I felt like there wasn't anybody that was going to do anything to me (.) no matter what they were going to do (.) I was comfortable that you know I could (1) don't get me wrong (.) it wasn't arrogance this (.) it was a kind of (.) sort of (.) let them worry about me

During this stage players acquired a mental state that superseded the details of what they were doing. They developed a comfort in performance that was borne of years of professional diligence. The result was self-focus, self-belief and delivery of optimal performance efficiency, even when things were not going well and required some inventiveness.

- Player C: Bayern Munich is the greatest example in 99 (1) we were poor for 77 minutes (1) Becks was our best player but he played central midfield with Butty 'cause Keaney and Scholesy were out (1) Becks went to the right (.) Sheringham came on (.) Butty went in the centre on his own and the whole game changed (1) what I'd done that season was overlap Becks and put crosses in (1) all of a sudden he came out to the right (.) Yorkie went back into midfield (.) Giggsy went to the left cause he'd been playing on the right (.) Coley went off Jesper went off and Ole went up front with Teddy and all of a sudden everything changed

Planning underpinned the players' ability to change and successfully implement a new strategy as an individual and a team. This was often demonstrated under extreme pressure in a major final with few minutes of play remaining. In this example, the game was won 2-1 after being 1-0 down at the time of change;

- Player C: European games I would ask for a video (1) I never liked watching picked or selected clips of teams by a coach (.) I have always liked to see the first half an hour of a match (.) cause I (.) er (.) for me (.) I (.) you can sort of see a player dribbling at somebody three times but I'm not really interested in that to be honest (.) that's probably the most obvious thing to look at (.) I'm looking at sort of (.) erm (.) who gives him the ball (.) when do they give him the ball (.) what movements does he make to get on the ball (.) what weaknesses does he have (.) is he lazy (.) does he follow you back (.) you know (.) they don't show you all these things in selected clips when the team are present

These examples illustrate how players remained inspired by playing for this club. They demonstrated ownership, personal diligence, professional preparation and maximal use of video analysis are important in this stage. Players typically explained how they went beyond the usual teamprovision and concerns to leave no stone unturned in the quest for knowledge and solutions for their role in the next game. 
- Player C: you are just switching on (.) you're thinking who am I playing against (.) right (.) what's he do (.) what do I need to do (.) do I need to watch a video of him (.) what do I need to practice in training (.) so what do I need to do in the training session (.) is he quick and jinky (1) so I'll get somebody to run (.) somebody to run to me quick and jinky (.) is he physical so I practice my heading and that's the sort of prep' or what I call more specific preparation

Preparing for games involved researchand planning a personal work schedule to be ready for that game. One player detailed his train of thought and cycle of action running into a major fixture. This involved task-specific selective attention and attentional control.

- Player C: playing against Brazil 15 years ago(.) you know (.) when Ronaldo was playing for them (.) Roberto Carlos in his pomp (.) I don't think you had to concentrate more (.) the level of concentration I don't think should change through time (1) I think player's speed changes but then you change with that as well (1) that's a decision to make that you give yourself more space (.) if he's quicker than you that's not a case (.) that you have to concentrate more

Another example provides an operational snapshot of cognitive re-structuring in action, to deal with a possible pressure situation in a high stakes game.

- Player C: always give them a positive as well (.) you always find a way particularly if you are giving members of your team sort of advice (.) you always pick on the positives (1) let's say it's Becks playing against (Player X) early on in our career (.) you don't say (.) Becks he's going to kick lumps out of you (1)you'll turn round to him and say Becks (.) honestly (.) every time you get the ball (.) pass and move (.) he'll (Player X) be tired after half an hour (1) so what you're telling him there is (.) don't hang on to the ball because you are going to get smashed (.) but you're doing it in a different way (.) you know (.) and to be honest with you (.) you don't give a negative (.) you just wouldn't do that (1) I don't do that (1) I don't know Man United players who do that

At the same time, there was clear evidence of vigilance for keep players 'fresh' across long league seasons.

- Player B: our manager wasone of the first to realize (.) Imean he's not played the same league team for 3 (.) 4 (.) 5 years cause he's realised now (.) Wednesday Saturday Wednesday Saturday you cannot keep the same level offitness mental and physical ability in those matches continually (.) you cannot do it (1) players need a break you know (.) you need a rest.

\section{DISCUSSION}

This study set out to address the shortfall of in-depth accounts of the lives of football players as they develop elite status and serial success. The research is founded in interviews with serially successful players, supported by triangulated accounts from a coach and also a parent of one player. The accounts are first hand from staff of one of the world's most successful modern-day football clubs, Manchester United. A systematic developmental process comprising four main stages of development and a fifth stage of excellence emerged from prolonged interviews. This system comprised 50 micro components across the lifespan. Evidence shows high level intricate engagement and a contemporary curriculum for delivering high level performance in European football.

Although Cote's model [17] of a talent-expertise based approach is the most cited to date in scientific literature [Bruner 15], the current study offers a robust base from which to investigate football-specific talent development and expertise. The rich and acute existential data revealed by the participants of this study draw us to a visceral and enlightening insight into the world of serial high performance within professional football. This updates the alignment of existing science with new high performance data to provide a model that is advanced, all-encompassing and football-specific. While concurring with 
deliberate play [17] being appropriate to progress through the early stages towards sporting eliteness, the new data provided here adds to that. More specifically, it emphasises the whole span of talent development in a football-specific context, through to sustained excellence and serial winning.

There are a number of key findings from the study. First, talent development through to serial winning followed five life stages. This moves from the generic models that drive contemporary academic commentary e.g., Bloom, [16], Côte, [17], Hendry and Kloep, [28], to a football-specific talent development/high level performance model. Second, while these findings highlight the purposefulness of time spent in the academy, they also show that while club staff had high expectations, players who emerged as particularly successful within it, demanded even more of themselves to become exceptional. The exceptional modern day player appears diligent, cognitively and practically curious and makes demands of himself that go far beyond the standard expectations, daily practices, and practice protocols of the club. Additionally, they show - albeit tangentially - that having a relatively stable group of team mates allows players to take some things for granted, especially the ways that others will react and provide support. These findings provide a useful barometer for considering current practice and culture in professional football clubs.

Third, the study provides important evidence that the lifespan of a serial winning professional footballer exists on an evolutionary continuum. Many of the 50 micro components are repeated as players pass through the respective stages. However, the components continuously evolve in terms of detail, quality, execution and purpose. To thrive in this situation, players are willing to develop and to extend their expertise from the start to the end of the professional journey. Our evidence also points to the shifting importance of each component as the bridges from development to maintenance are crossed; arguably, a serial winner's work is never complete. Once a player becomes competent or comfortable with any given micro-component, that component is then allocated maintenance time rather than being a primary focus. However, all such components are subject to ongoing monitoring by the player.

Both modern day football development and ultimate performance is a topic of vast debate, expenditure, and professional focus $[29,30]$ and academic findings of this nature can provide a way forward as an evidence based template for clarity and progression. The information presented in the current study offers a way to improve contemporary practice in the managerial chain, to sharpen cross-disciplinary appointments at the senior level and to refine understanding of the player/coach dynamic. The rich, practice-based evidence presented here offers insights for applied practitioners, governing bodies and football clubs' research and development departments. It also provides a map for football-based education programmes, a barometer of high level performance standards while also suggesting protocols that other professional clubs can use to assess progress. Such assessments would gauge players in the development stage for their likelihood of success within football academies, and at senior level for assessing how well daily operations influence first team environments and team success. In this period, Manchester United was a global, serial winning club. Their culture expected winning, and practice standards were enforced/enacted to ensure that winning was likely. The club promoted the belief that the team, its sub-units and individual players were never bored by working hard; they endorsed the view that their work ethic drove extended superior performance. The club supported, educated and encouraged their youth players to integrate this approach into their approach and to show those players that it was always central to every level of success at Manchester United. Within this football club it is evident that there were few divisions or barriers between youth and first teams, nor between players and staff. Equally, opportunity was ever-present, meaning that dreams could be fulfilled through compliant engagement in a rich all-encompassing system.

Although the context of their games - and competitions - was ever-changing, the Manchester United 'culture' was stable, with a (relatively) stable cast of people; importantly, that 'culture' included knowing how to handle match results. While the aim was winning, this was - mostly - celebrated quietly. When failure was evident, the club enacted a mechanism of 'feedback-and-reevaluate', which players knew would be implemented. Importantly, losing rarely brought ideas of alarm or catastrophe and this helped players to quickly re-engage with the 'hard work' ethic that underpinned all club training and practice. 


\section{LIMITATIONS AND FUTURE DIRECTION}

Inevitably, the study is limited by the level of triangulation that can be provided by this small sample from within a single club. There are only three or four other clubs who can match this club's record for serial success, and that accessing the accounts of such 'insiders' to those clubs is problematic. Future research could deploy longitudinal designs in these clubs and draw more representative samples. Other studies may favour pursuing the development of players in particular playing units, e.g., defenders or forwards. Ideally though, studies are needed that draw on other high performance clubs and comparative analysis from less efficient clubs playing in elite level competitions. While not a central focus, it is noteworthy that these players were able to contribute perspectives about the behaviours that enabled them to transfer from club preparation and play to national team duty. Importantly, this transfer also corresponded with national team success. Future studies could explore the utility of different preparatory approaches for different challenges among elite players. This would enhance the development of deliberate practice theory.

\section{CONCLUSION}

High performance association football is under-represented in contemporary academic commentary, and talent development models within the sport warrant domain-specific investigation. Consistently high-level performers at Manchester United deployed uniquely intensive developmental behaviours and routines. The culture of the club was facilitative and encouraging of their intensive individualistic behaviour. The evidence-based, football specific, evolutionary, and systematic approach to development and performance has also been seen to provide success on a global scale for the Germany footballing system, 2004-14 [31]. However, albeit that it is important to consider best practice in a holistic manner, future models should always be developed with an eye on the culture where they must reside [32]. This study offers a template for clubs, governing bodies and educational institutions to address improvement and serial senior level success in association football.

\section{REFERENCES}

1. The Premier League, Elite Player Performance Plan, The Premier League, London, 2011

2. Ericsson, K.A., Krampe, R.T., and Tesh-Romer, C., The Role of Deliberate Practice in the Acquisition of Expert Performance. Psychological Review, 1993, 100(3), 363-406.

3. Ericsson, K.A., and Lehmann, A.C., Expert and Exceptional Performance: Evidence of Maximal Adaptation to Task Constraints. Annual Review of Psychology, 1996, 47, 273-305.

4. Ericsson, K. A., The Acquisition of Expert Performance: An Introduction to Some of the Issues, In: Ericsson, K.A., eds., The Road to Excellence: The Acquisition of Expert Performance in the Arts and Sciences, Sports, and Games, Mahwah, NJ: Erlbaum, 1996, 1-50.

5. Ericsson, K. A., The Development of Elite performance and Deliberate Practice: An Update from the Perspective of the Expert-Performance Approach, in: Starkes, J an Ericsson, K.A, eds., Expert Performance in Sport: Recent Advances in Research on Sport Expertise, Champaign, IL: Human Kinetics, 2003, 49-81.

6. Ericsson, K. A., The Influence of Experience and Deliberate Practice on the Development of Superior Expert Performance, in: Ericsson, K.A., Charness, N., Feltovich, P and Hoffman, R. R, Eds., Cambridge Handbook of Expertise and Expert Performance, Cambridge, UK: Cambridge University Press, 2007, 685-706

7. Gladwell , M., Outliers. Penguin. London, 2009. 
8. Coyle, D., The Talent Code. Highbridge, 2009.

9. Syed, M., Bounce, Fourth Estate, London, 2011.

10. Ankersen, R., The Goldmine Effect. Icon. London. 2002.

11. Shenk, D., The Genius In All Of Us, Random House. London, 2012.

12. Epstien, D., The Sports Gene. Yellow Jersey, Random House. London, 2014.

13. Van Gog, T., Ericsson, K. A., Rikers, R. M. J. P., and Paas, F., Instructional Design for Advanced Learners: Establishing Connections Between the Theoretical Frameworks of Cognitive Load and Deliberate Practice. Educational Technology, Research, and Development, 2005, 53, 73-81.

14. Helsen, W.F., Hodges, N.J., Van Winckel, J., and Starkes, J.L., The Roles of Talent, Physical Precocity and Practice in the Development of Soccer Expertise. Journal of Sports Sciences, 2000, $18,727-736$.

15. Bruner, M.W. Ericsson, K.A. Wilson, B. and Côté, J., An Appraisal of Athlete Development Models Through Citation Network Analysis. Psychology of Sport and Exercise, 2009, 11, 133-139.

16. Bloom, B., Developing Talent in Young People. New York, Balantine, 1985.

17. Cote', J., The Influence of the Family in the Development of Talent in Sports, Sports Psychologist, 1999, 13, 395-417.

18. Abbott, A. and Collins, D., Eliminating the Dichotomy between Theory and Practice in Talent Identification and Development: Considering the Role of Psychology, Journal of Sports Sciences, 2004, 22, 395-408.

19. Kreiner-Phillips, K., and Orlick, T., Winning After Winning: the Psychology of Ongoing Excellence. The Sport Psychologist, 1993, 7, 31-48.

20. Moyes' boys. Retrieved from http:/www.dailymail.co.uk/sport/football/article2328338/Manchester-United-youth-players--David-Moyes-boys.html, 2014.

21. When it comes to Giving Youth a Chance and Producing Players for England, United Really Are Different Class. Retrieved from http $/ /$ www.dailymail.co.uk/sport/football/article2317233/Manchester-United-different-class-producing-youth-players--NeilAshton.html\#ixzz33VgXLJEd, 2014.

22. Johnson, T., Martin, A.J., Palmer, F.R., Watson, G., and Ramsey, P.L., A Core Value of Pride in Winning: The All Blacks' Team Culture and Legacy. The International Journal of Sport and Society, 2013, 4, 1-14.

23. Marshall, I.,Class of '92', Simon and Schuster, 2013.

24. Côté, J., Ericsson, K. and Law, M., Tracing the Development of Athletes Using Retrospective Interview Methods: a Proposed Interview and Validation Procedure for Reported Information, Journal of Applied Sport Psychology, 2005, 117, 1-20.

25. Denzin, N.K., and Lincoln, Y.S., Introduction: The Discipline and Practice of Qualitative Research, in: Denzin, N.K., and Lincoln, Y.S., eds., Handbook of Qualitative Research, (2nd ed), London: Sage Publications, 2000, 1-44. 
26. Jefferson, G., Glossary of Transcript Symbols With an Introduction, in: Lerner, G.H., ed., Conversation Analysis: Studies From the First Generation, Amsterdam: John Benjamins, 2004, 1331.

27. Côté, J., Salmela., J.H., Baria, A., and Russell, S., Organizing and Interpreting Unstructured Qualitative Data, The Sport Psychologist, 1993, 7, 127-137.

28. Hendry, L., and Kloep, M., Lifespan Development: Resources, Challenges and Risks, Oxford: The Alden Press, 2000.

29. English Football 'At a Crossroads', says FA's Head of Elite Development. Retrieved from http://www.theguardian.com/footbal//blog/2013/jun/04/english-fa-elite-development-danashworth, 2014

30. The F.A., Dyke Reveals Commission Makeup. Retrieved from http://www.thefa.com/news/2013/oct/greg-dyke-fa-commission-announced, 2014

31. Germany's Destruction of Brazil Was a Decade in the Making as Fostering Talent Through Academies Pays Off. Retrieved from http://www.telegraph.co.uk/sport/football/worldcup/10955553/Germanys-destruction-of-Brazil-was-a-decade-in-the-making-as-fostering-talentthrough-academies-pays-off.html, 2014.

32. England Cannot Copy Germany. Retrieved from http://www.bbc.co.uk/sport/0/football/28292358 2014 